\title{
Extremely large telescopes and the developing nations
}

\author{
J.O. Urama ${ }^{1} \dagger$, and P.N. Okeke ${ }^{1,2}$ \\ ${ }^{1}$ Department of Physics \& Astronomy, University of Nigeria, Nsukka, Enugu State, Nigeria \\ email: johnson@hartrao.ac.za \\ ${ }^{2}$ Centre for Basic Space Science, Nsukka, Enugu State, Nigeria \\ email: okekepius@yahoo.com
}

\begin{abstract}
The extremely large telescopes (ELTs) are built at huge financial cost and usually involve partnership among several bodies/nations. Consequently and naturally, telescope time allocations in many, if not most, of such telescopes are based either directly or indirectly on the monetary contributions of the partners. This paper examines the economy, sociology, science and politics of the ELTs and their implications for the astronomers and/or astronomy in poorer developing nations.
\end{abstract}

Keywords. sociology of astronomy, history and philosophy of astronomy, telescopes

\section{Introduction}

The current generation of large optical/infrared telescopes, constructed over the past 15 years worldwide, has required an investment equivalent to approximately 2 billion US dollars, or approximately $\$ 130$ million per year (Stepp, Daggert \& Gillett 2003). In many (if not most) of these very large telescopes, observing time allocations are based on contractual obligations to the consortia who built the instruments (the actual fraction of time defined on the basis of the existing contractual commitments). Astronomers in the developing countries, just like their counterparts in the developed world need access to large telescopes if they are to continue with cutting-edge research in observational astronomy. The big question is, how could the astronomers in poorer developing nations (who constitute about $20 \%$ of the IAU Membership) get "some guaranteed time" for such front line research in very large telescopes?

\section{Funding of Astronomy in Developing Nations}

\section{1. $R \& D$ in developing nations}

The term "developing nation" is used to denote nations with a low UN Human Development Index (HDI). Many "developing" countries are located in Africa, Latin America, and Asia. In 1999, the world population reached 6 billion. These 6 billion people live in 192 countries that lie across a vast spectrum of development. Some 30 developed countries in the so-called 'North' (mostly Australia, western Europe, Japan and North America) are home to fewer than one billion people or just 16 per cent of the world population. These people live a desirable quality of life, as reflected through such indicators as economic well-being and access to health-care. At the other end of the spectrum, the United

$\dagger$ Presently on leave in the Department of Industrial Physics, Ebonyi State University, Abakaliki, Nigeria 
Nations Conference on Trade and Development (UNCTAD) recognizes 50 nations, home to more than 1.2 billion people, as the world's least developed countries (LDCs), where the average income is less than US $\$ 1$ a day. Spanning these two extremes are about 100 developing nations, where the quality of life is higher than in the LDCs, but far below that achieved in the world's most developed countries (TWAS, 2004).

Today, science in the North continues to dominate the global scientific agenda. 80 percent of all scientists live and work in the North, which is home to less than 20 percent of the world's population. In a study in 2001 of the 1000 most-cited astronomy papers by host institution (of first author), being one of the ways to measure scientific impact, a very poor showing is observed for developing nations (Benn \& Sanchez 2001). However, certain developing countries may have high level capabilities in one or more scientific disciplines. The Philippines, for example, is an international leader in rice research, Chile is strong in astronomy, China conducts world class research in seismology, and India is considered among the world's best in mathematics. Africa is home to about half of the developing nations and there is little wonder that it has been argued (Zingu 2004) that, "to excel in physics research in Africa is to conquer Mount Everest without the aid of additional oxygen. In a continent that lacks the infrastructure of research laboratories, technical support, and so forth, relatively few physicists have managed to perform at levels competitive with the best in the world". This argument is even more pertinent to astronomy given the amount of money involved in building and running large telescopes needed for cutting edge research and the low level of public and governmental support to astronomy in Africa.

The quantum of money a country could invest in astronomy depends, among other things, on the economic well-being of the country and this 'economic well-being' is reflected by the nation's gross domestic product (GDP) - the value of all goods and services produced domestically. The purchasing power parity (PPP) is applied, together with the GDP in measuring the "economic strength" of nations as PPP involves the use of standardized international dollar price weights, which are applied to the GDP produced in a given economy. Figure 1 shows the GDP/PPP per capita for a selection of developed and developing countries. While the developed countries are characterized by high GDP/PPP per capita, the developing countries generally have values $\leqslant 10000$ US $\$$. Even more worrisome is the percentage of this GDP that such countries invest into Research and Development (R \& D), as shown in Figure 2.

\subsection{Astronomy funding in Nigeria: a case study}

Nigeria is the world's most populous back nation and a typical developing nation. In this country, only $0.62 \%$ (representing US $\$ 28$ Million) was allocated to the Ministry of Science and Technology and its 41 parastatals in the Fiscal Year 2004†. Out of this amount, the Centre for Basic Space Science, Nsukka (which is charged with the responsibility of conducting and coordinating all astronomy and other related researches and programs got only a paltry US $\$ 200000$ (representing $0.8 \%$ of the allocation to the Ministry). Table 1 compares the level of astronomy funding in Nigeria with that in some developed countries which shows that Nigeria, like nearly all developing nations, is under funded by several orders of magnitude. Although funding is a global problem, for a country with little or no interest in the modern scientific approach to the skies, a country that is only interested on the practical applications of science and whose role models are the rich (irrespective of how the wealth was acquired), the problem is far worse than might be imagined.

$\dagger$ http://www.budgetoffice.gov.ng/docs/budgets/budgetdetail.pdf 


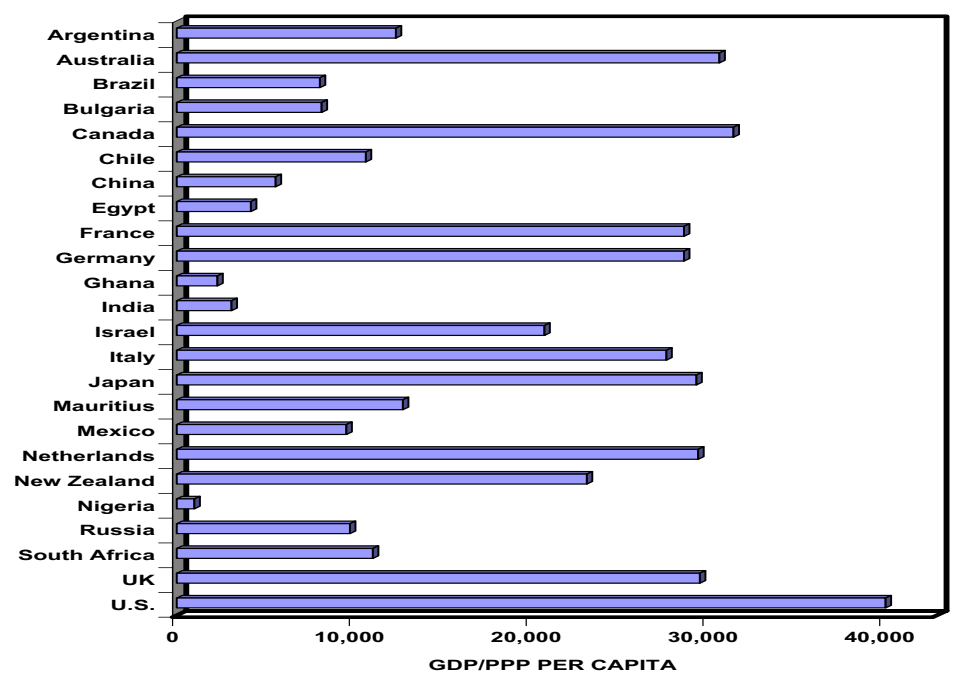

Figure 1. GDP/PPP per capita for a selection of developed and developing countries. (Data were obtained from http://www.infoplease.com/ipa/A0874911.html).

Samuel Okoye, the first black African to obtain a doctorate in radio astronomy, happens to come from Nigeria. His doctoral research at the Mullard Radio Astronomy Observatory, University of Cambridge, led to the discovery (with his supervisor, Dr Tony Hewish) of an extremely high brightness temperature source in the Crab Nebula recognized as the first example of a neutron star. This source later turned out to be none other than the famous Crab Nebula Pulsar. The discovery was widely recognized as being of fundamental importance to basic physics. He returned to Nigeria to set up a radio observatory an ambition that very well highlights the problems, challenges and prospects of doing astronomy in many of the developing nations. According to Okeke (1999), "Professor Okoye's initial efforts to set up a space research centre were frustrated by lack of funds until in 1977 when the late Dr. Nnamdi Azikiwe made a handsome donation of the sum of one hundred thousand Naira (about US $\$ 150000$ then) towards the setting up of a space centre. With this initial assistance Professor Okoye and his group were able to set up a $10-\mathrm{m}$ dish operating at $327 \mathrm{MHz}$ as the initial facility of the group. This was done with a little assistance from University of California, and so a lot of indigenous technology was built in. With this facility, the centre planned to carry out the following projects: a two station pulsar observation with India, a VLBI observation programme with Germany, ... All these experiments involve signing of agreements with other governments and some financial support. There was no support from the Nigerian government or from any other source, as a result, all the above mentioned projects could not take of. Since no serious activity was taking place around the telescope, which was cited in a remote corner of the University as is usual with radio instruments, the dish and all the facilities were vandalized."

\section{Astronomers in developing nations and the "guaranteed time" on large telescopes}

Time allocation in all the extremely large telescopes are based on either the guaranteed time arising from contractual obligations to the consortia who fund the telescope 


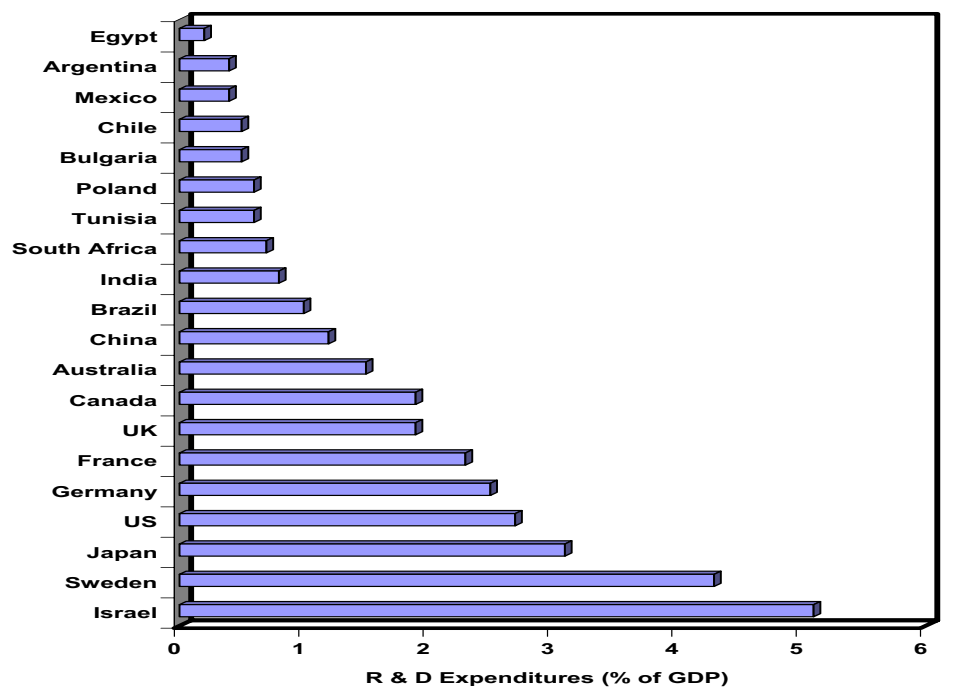

Figure 2. Percentage of GDP spent by some selected countries on Research and Development. Values based on data from the United Nations Educational, Scientific and Cultural Organization; aggregates calculated for the Human Development Report Office by the World Bank. Data refer to the most recent year available during the period $1997-2002$.

Table 1. Approximate comparisons of the funding level of astronomy in Nigeria (2004) with those of astronomy in typical developed countries (2002)

\begin{tabular}{lccccc}
\hline & Nigeria & Israel $^{a}$ & Netherlands & UK & USA $^{b}$ \\
\hline Astronomy Funding(US \$Million) & $<0.2$ & 6 & 45 & 174 & 3228 \\
Population (Million) & 130 & 6.1 & 15.8 & 59 & 288 \\
Astronomy Expenditure per head & 0.0015 & 1 & 3 & 3 & 11 \\
GDP (US \$Billion) & 72.1 & 129 & 481.1 & 1560 & 10400 \\
Astronomy Expenditure per GDP $\left(10^{-5}\right)$ & 0.3 & 5 & 9 & 11 & 31 \\
\hline
\end{tabular}

${ }^{a}$ Report of the Visiting Committee on Astronomy in Israel to The Israel Academy of Sciences and Humanities January 2002, http://wise-obs.tau.ac.il/astro-depart/astronomy_report_short.doc ${ }^{b}$ Astronomy funding in the NASA, NSF and OSS budgets. Source: Kevin B. Marvel, Astronomy in the FY 2002 Budget: http://www.aaas.org/spp/rd/xxvi/chap14.pdf.

and/or the scientific merit of the proposal and the importance of its contribution to the advancement of scientific knowledge. Most astronomers in poorer developing countries cannot meet any of those criteria due to poor funding, lack of access to even smaller telescopes (which would prepare them for large telescopes), or even lack of adequate interaction with the scientific community.

At about US $\$ 30$ million, SALT represents one of the powerful large telescopes built at a very low cost. The question, however, is whether even such a "cheap" telescope is affordable to the poorer developing nations. A $5 \%$ subscription to the telescope amounts to US $\$ 1.5$ million. For many, if not most, of the developing nations, this is unfordable as it could translate to the total spending on astronomy and related fields for a number of years. That being the case, could astronomers in such developing nations ever have an opportunity of carrying out some cutting edge astronomical research with large telescopes. In other words, is there any mechanism of providing some guaranteed observing 
time (no matter how small) for the astronomers from the poorer countries in very large telescopes without necessarily compromising the funding principles and obligations to other partners? One such possibility is for fund to be sourced 'externally' (through either an IAU Commission or other bodies such as the Third World Academy of Sciences (TWAS), COSPAR, etc) on behalf of the astronomers in developing nations. Such funding could provide for a maximum of $5 \%$ telescope time allocation to such astronomers from developing nations. The time, so guaranteed, would be administered by the body that sourced the fund in such a way that the quality of work done with the telescopes are not compromised either.

\section{Conclusions}

Some astronomers in developing countries have the training and capacity, but lack the funding, to do front line research in observational astronomy. In this generation of extremely large telescope (ELT) to overwhelmingly large telescope (OWL), it would be most unfortunate for these astronomers to be abandoned to doing only 'third-class research' simply because their nations are either too poor to fund astronomy or lack the interest and willingness to support them or both. One way out of this is for a Commission of the IAU or any other Agency to subscribe to some of these large facilities, through some donor funds, on behalf of astronomers from poorer developing nations and manage such subscription is such a way that neither telescope funding nor the research output is compromised.

\section{Acknowledgements}

JOU would like to acknowledge the partial support received from the International Union of Pure and Applied Physics (IUPAP). The travel sponsorship came from the International Cooperation Division at the Department of Science and Technology of the South African government.

\section{References}

Benn, C. \& Sanchez, S. 2001, The Isaac Newton Group of Telescopes (ING) Newsletter No. 4

Okeke, P.N. 1999, Basic Space Science and Technology in Nigeria in the 21st Century (Preparations for a take-of). A public lecture organised by the Nigerian Academy of Science

Stepp, L., Daggert, L. \& Gillett, P. 2003, Estimating the costs of extremely large telescopes, SPIE, 4840, 309

TWAS 2004, Building Scientific Capacity: A TWAS Perspective, http://www.ictp.trieste.it/ twas/pdf/CapBuildReport.pdf

Zingu, E. 2004, Physics Today 57, 37

\section{Discussion}

WHITELOCK: We have been very conscious of the importance of involving researchers from elsewhere in Africa in the Southern African Large Telescope (SALT), right from the planning stage. Even the name was chosen to signify that African involvement went beyond South Africa. However, doing this in a meaningful way is not trivial and giving people from Africa time on large telescopes only addresses a small part of the overall problem. There is a need for training and the development of linkages, collaborations and partnerships, before many people from developing countries will be able to seriously contribute to astrophysics research. South Africa astronomers started the National Astrophysics and Space Science Programme (NASSP) as a postgraduate training programme, but also as a way of encouraging young Africans from South Africa and elsewhere on 
the continent to see the opportunities of working together and working closely with our SALT partners. This is a unique programme being a collaboration between 8 South African Universities and 3 National Facilities. NASSP (www.star.ac.za), which has only been going for 3 years, has already trained students from Zambia, Zimbabwe, Uganda, Botswana, Kenya, Rwanda, Gabon and Ethiopia as well as South Africa. This broader African involvement has been a crucial factor in attracting funding from international donors, such as Ford and Mellon, without which NASSP would not have been possible. 